\title{
Spinal Dural Arteriovenous Fistulas: Clinical Experience with Endovascular Treatment as a Primary Therapy at 2 Academic Referral Centers
}

\author{
J.J. Gemmete, N. Chaudhary, A.E. Elias, A.K. Toma, A.S. Pandey, R.A. Parker, I. Davagnanam, C.O. Maher, S. Brew, and F. Robertson
}

\begin{abstract}
BACKGROUND AND PURPOSE: Spinal dural arteriovenous fistulas are a rare entity that, if left untreated, can lead to considerable morbidity with progressive spinal cord symptoms. The aim of this study was to evaluate the clinical outcome of patients with spinal dural arteriovenous fistulas that were primarily treated with endovascular embolization.
\end{abstract}

MATERIALS AND METHODS: A retrospective review was performed of all patients from 1997-2010 who underwent treatment at 2 academic referral centers for a spinal dural arteriovenous fistula. Follow-up was performed by clinical examination, and functional status was measured by use of the Aminoff-Logue Disability Scale, McCormick classification grading, and mRS scores. The nonparametric Wilcoxon signed rank test was used to compare pretreatment and posttreatment Aminoff-Logue Disability Scale gait and micturition scores, McCormick classification grading, and mRS scores. $P$ values $<.05$ were considered significant.

RESULTS: A total of 38 patients were included. Five patients (2 endovascular, 3 surgical) were lost to follow-up and therefore were excluded from the analysis, 29 patients were initially treated from an endovascular approach ( 9 Onyx, 20 cyanoacrylate), and 4 patients were treated from a standard surgical approach. Five patients in the endovascular group subsequently underwent surgery for various reasons. The clinical improvements in the Aminoff-Logue Disability Scale gait and micturition scores, McCormick classification grading, and the mRS scores were statistically significant $(P<.05$, Wilcoxon signed rank test).

CONCLUSIONS: We conclude that endovascular treatment of spinal dural arteriovenous fistulas can result in good clinical outcomes. Surgery remains the treatment of choice when safe embolization of the proximal radicular draining vein cannot be obtained or because the shunting artery of the spinal dural arteriovenous fistula also supplies the anterior spinal, posterior spinal, or a radiculomedullary artery.

ABBREVIATIONS: ALS = Aminoff-Logue Disability Scale; $M C=$ McCormick classification; $m R S=$ modified Rankin Scale; $S D A V F=$ spinal dural arteriovenous fistula

S DAVFs are the most common spinal vascular malformations accounting for $70 \%$ of the vascular lesions involving the spinal cord. ${ }^{1,2}$ The time between the onset of symptoms and diagnosis of the lesion is usually late in the disease course. This is because of the nonspecific clinical presentation. ${ }^{3,4}$ Patients may present with gait

Received October 17, 2012; accepted after revision December 27, 2012.

From the Departments of Radiology (J.J.G., N.C., A.E.E.) and Neurosurgery (J.J.G., N.C., A.S.P., C.O.M.), University of Michigan Health Systems, Ann Arbor, Michigan; Departments of Neuroradiology (I.D., S.B., F.R.) and Neurosurgery (A.K.T.), National Hospital for Neurology \& Neurosurgery, University College London Hospitals, London, United Kingdom; and Department of Biostatistics (R.A.P.), School of Public Health, University of Michigan, Ann Arbor, Michigan.

Paper previously presented at: World Federation of Interventional \& Therapeutic Neuroradiology (WFITN) Congress, November 8-11, 2011; Cape Town, South Africa.

Please address correspondence to Joseph J. Gemmete, MD, Department of Radiology, Neurosurgery, Otolaryngology, Division of Neurointerventional Surgery, University of Michigan Health Systems, UH BID 328, 1500 E. Medical Center Dr, Ann Arbor, MI 48109; e-mail: gemmete@med.umich.edu

三 Indicates article with supplemental on-line tables

http://dx.doi.org/10.3174/ajnr.A3522 disturbances, difficulty climbing stairs, sensory symptoms, and even radicular pain that may affect 1 or both extremities. The neurologic symptoms show progression with time. ${ }^{5}$ Bowel and bladder incontinence, erectile dysfunction, and urinary retention are seen late in the course of the disease process. ${ }^{6}$ If the lesion is not treated, $50 \%$ of patients will become severely disabled and $<10 \%$ will be able to walk independently after 3 years. ${ }^{7}$ The lesion is thought to be an acquired fistula of the dural branch of a segmental artery draining into a radicular vein at the dural sleeve of the nerve root. ${ }^{8}$ SDAVFs can be treated by surgery with clip placement or coagulation of the vein from a posterior spinal laminectomy approach. ${ }^{9}$ Endovascular embolization is an effective therapy in the treatment of SDAVFs and can be used as a definitive intervention in most patients. ${ }^{10}$ The success of endovascular treatment is believed to be dependent on complete occlusion of the proximal radicular draining vein and the site of the fistula itself. ${ }^{10}$ The goal of treatment, regardless of the type of intervention, is to eliminate the abnormal arteriovenous communication to avoid progression or 
worsening of the neurologic symptoms. The aim of our study was to evaluate the clinical outcome of patients with an SDAVF primarily treated with endovascular embolization.

\section{MATERIALS AND METHODS}

A retrospective chart review was performed to identify all cases of patients with SDAVFs seen at 2 tertiary academic medical institutions from 1997-2010. The institutional review board of both academic referral centers granted approval of the study.

The medical records of these patients were retrospectively reviewed, and clinical history, neurologic examination, and diagnostic work-up were obtained. Patients were evaluated in clinics attended by neurosurgeons, neurologists, and interventional neurologists. Information collected included patient demographics, clinical presentation, location of the fistula, years of symptoms before diagnosis, treatment, duration of follow-up, and the functional status (preoperative and postoperative). Functional status (gait and micturition) was measured by use of the ALS, MC, and mRS, calculated retrospectively from the preoperative and postoperative clinical notes. The interval between the onset of initial symptoms and diagnosis of SDAVF by angiography was calculated as the time of diagnosis. All suspected lesions on MR imaging were confirmed by digital subtraction angiography. Preoperative MR imaging was performed in all patients. Postoperative MR imaging was available for 15 patients at 1 institution; at the other institution, we could not obtain the posttreatment MR imaging reports.

If available, pre- and posttreatment imaging characteristics were compared. The treatment strategy was identical for all patients; an attempt at endovascular obliteration was the first choice of treatment. Surgery was offered whenever embolization failed or was abandoned for technical reasons.

\section{Technique of Endovascular Embolization}

All spinal angiograms were performed with the patients under general endotracheal anesthesia (with somatosensory- and motor-evoked potentials in some instances) to avoid patient discomfort and minimize motion artifacts. Both angiographic suites are composed of a biplane angiographic unit with conebeam CT capability (Axiom Artis; Siemens, Erlangen, Germany). Patients were placed supine on the angiographic table, and transfemoral access and sheath placement was obtained by use of a modified Seldinger technique. All patients were given intravenous hepa$\operatorname{rin}(70 \mathrm{U} / \mathrm{kg}-100 \mathrm{U} / \mathrm{kg})$ to maintain an activated coagulation between 250 and $300 \mathrm{~s}$. Spinal angiography was performed in all patients to identify the anterior and posterior spinal arteries and the site of the fistula. After the diagnostic portion of the procedure, a $4 \mathrm{~F}$ or $5 \mathrm{~F}$ catheter was placed in the segmental artery supplying the SDAVF.

Coaxially, through the catheter, depending on the liquid embolic agent used, a Prowler 10 (Codman Neurovascular, Raynham, Massachusetts), Magic (Balt, Montmorency, France), Echelon 10 (ev3 Neurovascular, Irvine, California), or Marathon (ev3 Neurovascular) microcatheter was advanced under road-mapping over a microwire to reach the most distal aspect of the segmental artery supplying the SDAVF. Microcatheter angiography was performed to determine microcatheter position and if there was filling of the anterior spinal, posterior spinal, or a radiculom- edullary artery. If a question arose about the safety of the selective microcatheter position for those cases performed with Onyx, a provocative test was performed with $1 \mathrm{mg}$ of methohexital sodium (Brevital) and $15 \mathrm{mg}$ of preservative-free $2 \%$ lidocaine hydrochloride. Embolization was not performed if a 50\% reduction in amplitude of the motor-evoked potential on monitoring was demonstrated.

Endovascular embolization of the SDAVF was performed with Onyx (ev3 Neurovascular) or with cyanoacrylate glue ( $n$-BCA; Codman Neurovascular), Glubran 2 (GEM, Viareggio, Italy), or Histoacryl (Braun, Melsungen, Germany). The aim of the embolization was to penetrate the liquid embolic agent into the proximal draining vein while occluding the fistula site and feeding arterial vessels. Repeated segmental angiography after embolization was performed bilaterally at the level of the arterial feeder and the adjacent 2 segmental levels above and below the site of the fistula.

After the procedure, the patient was admitted to the neurointensive care unit for close monitoring for $24-48$ hours. If the patient's condition deteriorated in the immediate postoperative period, the patient was given heparin and a subsequent angiogram was performed.

\section{Surgical Technique}

Surgery was uniform throughout the study period. A midline laminectomy was performed 1 level above and 1 level below the fistula. The dura was opened in the midline, the fistula identified, and the draining radicular vein coagulated and divided. The dural nidus at the nerve root was coagulated whenever possible.

In patients harboring a common segmental artery supplying the fistula and an anterior spinal artery, endovascular embolization was not attempted, and those patients were referred for surgery. Embolization was considered a failure if the liquid embolic agent did not penetrate the proximal shunting radicular vein. If embolization failed to occlude the fistula as shown by postembolization angiography, surgery was performed immediately. Furthermore, surgery was performed in those patients with severe atheromatous disease or a tortuous feeding artery where catheter navigation near the site of the fistula could not be obtained.

\section{Follow-Up}

Occlusion of the fistula was confirmed by repeated spinal angiography in all patients before discharge from the hospital. Depending on the treatment approach, neurologists, neurosurgeons, and/or interventional neuroradiologists obtained clinical follow-up. Spinal angiogram and MR imaging were obtained at 6 months after treatment in all patients; however, we were only able to review the follow-up MR imaging results in 15 patients at 1 institution. If there was a delay in recovery or a clinical concern for residual or recurrent disease, MR imaging and angiography studies were repeated.

\section{Statistical Analysis}

Data were summarized by descriptive statistics, including percentages and counts for categoric data and means and SDs for continuous data. Statistical analysis was performed by use of the software program SAS 8.02 (SAS Institute, Cary, North Carolina). All statistical tests were 2-tailed. The nonparametric 

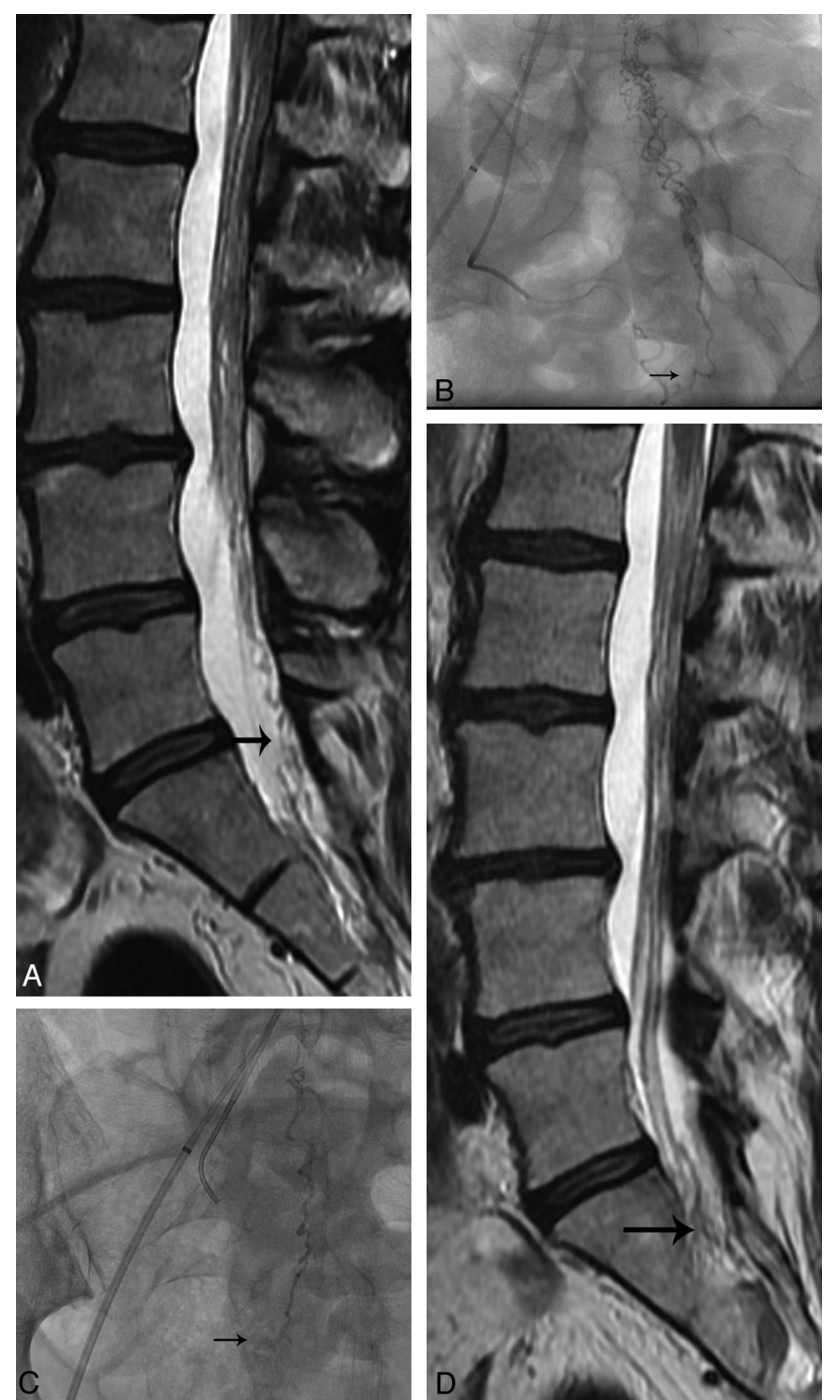

FIG 1. Patient 15, a 66-year-old man with a history of bilateral lower extremity weakness. A, Sagittal T2-weighted MR image shows multiple serpiginous flow voids (arrow) within the sacrum and lower lumbar spine. B, Left anterior oblique right lateral sacral angiogram shows site of SDAVF (arrow). C, Frontal spot fluoroscopic image shows glue cast within the arterial feeder, site of the fistula, and outflow vein (arrow). D, Sagittal T2-weighted MR image 6 months after treatment shows some interval resolution of the multiple serpiginous flow voids (arrow) within the sacrum and lower lumbar spine.

Wilcoxon signed rank test was used to compare pre- and posttreatment ALS gait and micturition scores, MC grading, and mRS scores. $P$ values $<.05$ were considered significant. Because of the retrospective design and the small surgical sample size, no statistical comparison between the 2 treatment techniques was performed.

\section{RESULTS}

Between 1997 and 2010, a total of 38 patients were treated for an SDAVF. Our study population included 33 patients (26 men and 7 women; average age, 64.6 years; age range, $39-81$ years) who were available for long-term follow-up. Twenty-nine patients were treated from an endovascular approach (9 Onyx, 20 -BCA) (Figs 1 and 2), 5 patients from an endovascular followed by a surgical approach, and 4 patients from a surgical approach. Five patients were lost to follow-up ( 2 endovascular, 3 surgical) and therefore were not included in the analysis. Diagnosis of SDAVF was confirmed by spinal angiography. Clinical presentation included the following: of the 33 patients, lower extremity weakness was seen in 29 (88\%), patchy dermatomal symptoms in 25 (76\%), nonspecific back pain in 17 (52\%), and urinary symptoms in $9(27 \%)$. The average duration of symptoms before treatment was 24.6 months (range, 1-84 months). In this series, there were 5 sacral, 9 lumbar, 12 low thoracic (T8-T12), and 6 midthoracic fistulas (T4-T7); and 1 cervical fistula (Fig 3). Most of the fistulas had a single segmental arterial feeding artery; however, there were 2 fistulas that demonstrated multiple feeding arteries. There was 1 treatment-related complication. One patient had clinical deterioration of clinical symptoms after penetration of the embolic material too far into the venous system; however, this improved after administration of heparin. The mean interval follow-up was 13 months (range, 1-120 months).

According to preprocedure and postprocedure ALS, improvement in gait was seen in 15 of 33 patients, and improvement in micturition was seen in 6 of 33 patients (On-Line Table 1). Gait and micturition stabilized in 17 of 33 patients and in 27 of 33 patients, respectively. One patient (Patient 30) experienced worsening of gait ALS and had been treated for an SDAVF at S2. This patient's symptoms probably worsened because of penetration of embolic material too far into the venous system. In the 9 patients treated with Onyx, improvement in ALS gait was seen in $5(56 \%)$ of 9 patients and ALS micturition in $3(33 \%)$ of 9 patients, respectively.

On MC grading, 15 (45\%) of 33 patients had improvement and $18(55 \%)$ had no change. No patient showed worsening of MC grading (On-Line Table 1). On assessment by mRS score, $14(42 \%)$ of 33 patients had improvement and 18 (55\%) had no change. One patient (3\%) showed worsening of the mRS score (On-Line Table 1). This patient was treated from an endovascular approach with $n$-BCA with the fistula at T12.

Two of the 20 patients in the cyanoacrylate group underwent repeated embolization. In these 2 patients, clinical deterioration at initial follow-up prompted a repeated diagnostic angiography study revealing a persistent SDAVF, which was treated with subsequent embolization. On final follow-up, both patients improved clinically based on ALS gait and micturition scores.

In the group who underwent embolization followed by surgery $(n=5), 2$ patients were initially treated with cyanoacrylate and 3 with Onyx. The first patient (Patient 2) was successfully treated with cyanoacrylate for an SDAVF at L4; however, clinical examination revealed worsening of this patient's condition, and a second angiographic examination was obtained. Results demonstrated formation of a collateral vessel. The patient was surgically treated because no safe position for embolization was available. The second patient (Patient 5) was treated for an SDAVF at L1; there was poor penetration of Onyx into the draining radicular vein. Patient 5 remained neurologically stable, but a repeated angiographic study showed persistent filling of the fistula. At surgical exploration, the arterialized vein could not be identified. The third patient (Patient 9) had 2 discrete SDAVFs with supply from T7 and $\mathrm{T} 12$, with the anterior spinal artery arising from $\mathrm{T} 12$. The T7 level was successfully treated with excellent penetration of cyanoacrylate into the draining radicular vein. Given the additional supply to the fistula from T12 (where the anterior spinal artery arose), surgery was performed. The fourth patient (Patient 13) had an SDAVF at C5. Onyx 

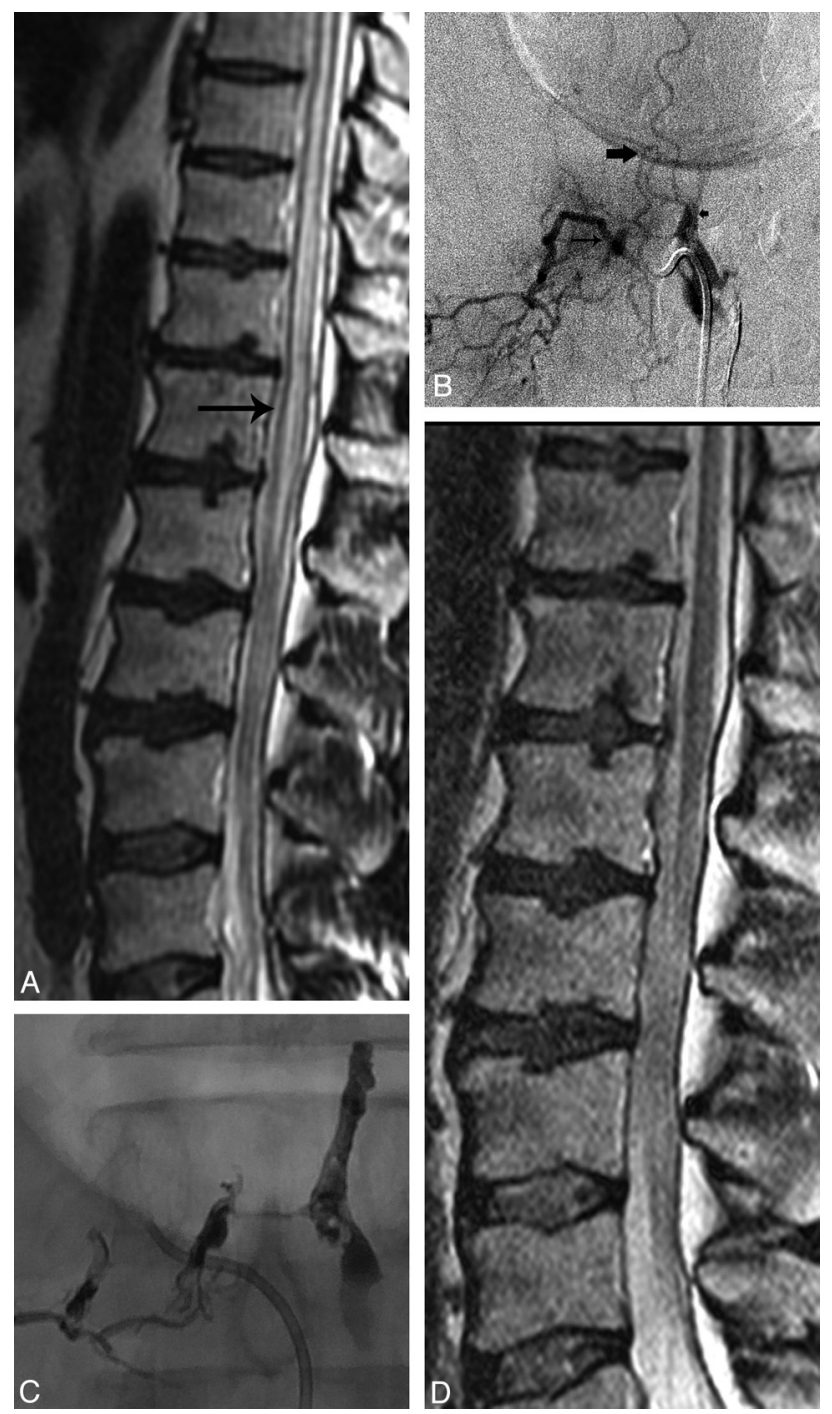

FIG 2. Patient 1, a 59-year-old man with inability to stand and persistent retention. $A$, Sagittal T2-weighted MR image shows high signal within the conus medullaris, lower and midthoracic spinal cord ( arrow). B, Right T12 angiogram shows filling of an SDAVF (small arrow) with initial filling of the epidural venous plexus (small arrow), which then fills the radicular veins (large arrow). C, Frontal spot fluoroscopic images showing Onyx cast. D, Sagittal T2-weighted MR image 3 months after treatment shows interval resolution of the high signal within the conus medullaris, lower and midthoracic spinal cord.

embolization was attempted; however, there was poor penetration into the draining radicular vein and we were concerned about nontarget embolization into the main vertebral artery, necessitating surgery. The fifth patient (Patient 16) had an SDAVF at L2 that was successfully treated with Onyx, with good penetration into the draining radicular vein. However, follow-up angiogram at 6 months demonstrated development of a collateral vessel to the fistula at L3, and surgerywas therefore performed. One patient had improvement in motor strength on the ALS scale, and $4(80 \%)$ of 5 patients demonstrated stable motor strength. According to MC grading, 2 $(40 \%)$ of 5 patients had improvement and $3(60 \%)$ of 5 had no change. On mRS assessment, 1 (20\%) of 5 patients had improvement and $4(80 \%)$ of 5 had no change.

The improvements seen after treatment in the ALS gait and micturition scores, MC grading, and the mRS scores were statis- tically significant $(P<.05$, Wilcoxon signed rank test) (Tables 1 and 2). Eight patients in the ALS micturition analysis and 3 patients in the MC grading analysis were excluded because their preintervention examination results were normal.

A total of 33 preoperative and postprocedure MR imaging scans were performed; however, we were able to only obtain such scans in 15 patients (On-Line Tables 2-4). Five patients had cord edema within the midthoracic region on preoperative MR imaging; in this group, 3 had no improvement on follow-up imaging, 1 had mild improvement, and 1 had moderate improvement. In the midthoracic group, 3 patients had improvement in the ALS gait score, but this score remained unchanged in 2 patients. The ALS micturition score remained the same in all 5 patients. Seven patients had cord edema in the low thoracic region on preoperative MR imaging; in this group, 2 had no change, 1 had mild improvement, and 4 had marked improvement. ALS gait score in this group improved in 5 and remained the same in 2 patients. ALS micturition score improved in 3 patients and remained the same in 4 . Only 2 patients had cord edema isolated to the conus medullaris on preoperative MR imaging; in this group, 1 had mild improvement and 1 had marked improvement in the extent of the edema. ALS gait and micturition scores improved in 1 patient and remained unchanged in the other patient.

\section{DISCUSSION}

SDAVFs arise from a spontaneous or acquired abnormal communication between a segmental radicular artery and the corresponding radicular vein at its site of dural penetration. SDAVFs are relatively rare, and their diagnosis is often missed because of nonspecific clinical symptoms at presentation. ${ }^{11-13}$ The delay to diagnosis in our patients (mean, 24.6 months) is comparable to other series. ${ }^{13-15}$ At the time of diagnosis 14 of 33 patients were severely disabled ( $\mathrm{mRS}>4$ ). This finding is also comparable to other reports. ${ }^{13-15}$ We did not correlate the severity of the clinical presentation with the time of diagnosis.

Most of our patients in our study were men (26/33), with an average age of 64.6 years. This finding also correlates with the demographics seen in several other large studies. ${ }^{11,14,15}$ We had only 1 patient younger than 40 years in our study, which illustrates the rarity of this diagnosis in the younger patient population.

Presenting symptoms in our patient population included the following: of our 33 patients, lower extremity weakness was seen in $29(87 \%)$, patchy dermatomal symptoms in $25(75 \%)$, nonspecific back pain in 17 (51\%), and urinary symptoms in 9 (27\%). These symptoms at clinical presentation are similar to those reported in other large series. ${ }^{3,14,15}$ Development of upper motor neuron signs with gait and micturition impairment is usually seen late in the course of the disease process. Early diagnosis and successful treatment of the fistula correlates with improvement in clinical symptoms. ${ }^{16}$ Even with successful treatment, late presentation is associated with poor clinical and functional outcomes.

Also in accordance with previous studies, most SDAVFs in our series orginated from the thoracic and lumbar levels, ${ }^{14,15,17}$ as demonstrated in Fig 3. Most of the fistulas had a single segmental arterial feeding artery; however, there were 2 fistulas that demonstrated multiple feeding arteries.

Several prior studies have reported results after endovascular 


\section{Fistulae distribution}

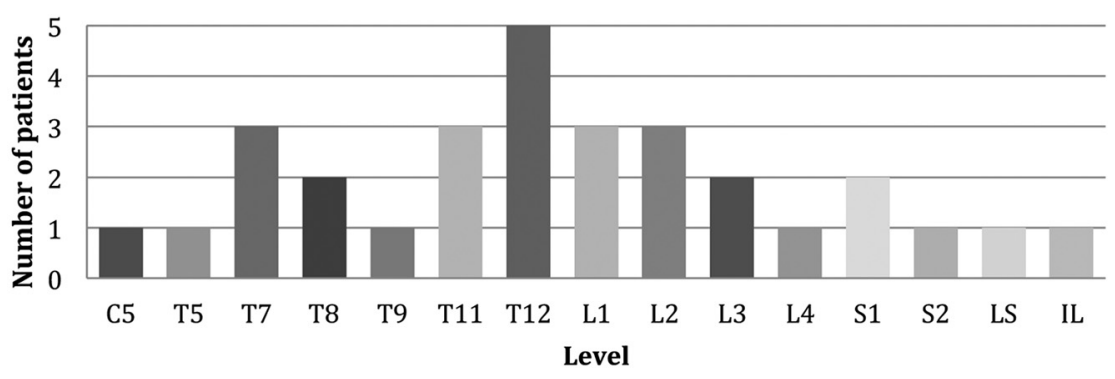

FIG 3. Site of fistulas. LS indicates lateral sacral; IL, lleolumbar.

Table 1: ALS functional grades before and after intervention

\begin{tabular}{lccc}
\hline & $\begin{array}{c}\text { Before Treatment } \\
\text { (Avg } \pm \text { SD) }\end{array}$ & $\begin{array}{c}\text { Last Follow-Up } \\
\text { (Avg } \pm \text { SD) }\end{array}$ & P Values \\
\hline Gait $(n=33)$ & $3.09 \pm 1.48$ & $2.51 \pm 1.46$ & ${ }^{*} .0021$ \\
Micturition $(n=25)$ & $2.24 \pm 0.77$ & $1.50 \pm 1.09$ & ${ }^{*} .025$ \\
\hline
\end{tabular}

* Values were statistically significant $(P<.05$; Wilcoxon signed rank test).

Table 2: MC and mRS scores before and after intervention

\begin{tabular}{lccc}
\hline & $\begin{array}{c}\text { Before Treatment } \\
\text { (Avg } \pm \text { SD) }\end{array}$ & $\begin{array}{c}\text { Last Follow-Up } \\
\text { (Avg } \pm \text { SD) }\end{array}$ & P Values \\
\hline $\mathrm{MC}(n=30)$ & $2.96 \pm 0.88$ & $2.36 \pm 1.06$ & ${ }^{\star} .0003$ \\
$\mathrm{mRS}(n=33)$ & $3.15 \pm 1.48$ & $2.60 \pm 1.51$ & ${ }^{\star} .0034$ \\
\hline
\end{tabular}

* Values were statistically significant $(P<.05$; Wilcoxon signed rank test).

treatment of SDAVFs. Niimi et $\mathrm{al}^{18}$ reported 49 patients who were primarily treated with $n$-BCA, but isobutyl-2-cyanoacrylate and polyvinyl alcohol were also used. According to these authors, adequate embolization was achieved in 39 patients ( $80 \%$ ); however, angiographic recurrence was seen in $8(23 \%)$ of the 35 patients. ${ }^{18}$ Westphal and $\mathrm{Koch}^{19}$ found recurrent fistulas in 20 (57\%) of 35 patients treated with embolization at a mean follow-up time of 7.5 months. In another reported series of 27 SDAVFs, Song et $\mathrm{al}^{20}$ showed a $25 \%$ failure rate in patients treated with $n$-BCA.

Furthermore, several studies have reported outcomes after embolization of SDAVFs. Eskander et $\mathrm{al}^{21}$ reported on their experience in 26 consecutive patients who were treated for a 6-year period. Nine (39\%) of the 23 patients in whom liquid acrylic embolization was performed or attempted ultimately required surgery. ${ }^{21}$ All patients were stabilized or their condition improved after definitive treatment, as assessed by the ALS. ${ }^{21}$ Van Dijk et $\mathrm{al}^{6}$ reported a cure rate of only $25 \%$ (11/44 patients) after treatment with $n$-BCA embolization. After failed endovascular treatment, 31 patients were cured surgically; the 2 other patients refused surgery. ${ }^{6}$ Motor and bladder function scores were significantly improved in 35 patients who had longterm follow-up (both $P<.005$ ). ${ }^{6}$ Sherif et al, ${ }^{22}$ in their study of 26 patients in which embolization with Histoacryl was performed in 19 patients $(73.1 \%)$ and direct surgery in 7 patients $(26.9 \%)$, reported a statistically significant improvement was seen in both the mRS score and the ALS gait scale score $(P<.05)$. In addition, Andres et $\mathrm{al}^{23}$ in a group of 21 patients showed that surgical and endovascular treatment resulted in significant improvement in ALS scores $(-62.5 \%$ and $-31.4 \%$, respectively; $P<.05)$ and a tendency toward improved mRS ( $-50 \%$ and $-32 \%$, respectively) scores. Furthermore, Narvid et $\mathrm{al},{ }^{3}$ in a group of 63 patients in whom 39 were treated by an endovascular approach and 24 by a surgical approach, reported a signifi- cant improvement was observed in ALS scores in both the endovascular and surgery groups (gait, $P<.001$; micturition, $P=.005)$. In our study, the improvements seen after treatment in the ALS gait and micturition scores were statistically significant $(P<.05$, Wilcoxon signed rank test). The clinical improvements in the MC grading and the $\mathrm{mRS}$ score seen after treatment were also statistically significant $(P<.05$, Wilcoxon signed rank test). Our study compares favorably with the other reports described above. In our study, the time from symptom onset to diagnosis of the SDAVF was 24.6 months. This finding may have influenced our results because, even with proper treatment, a long duration of initial neurologic symptoms is associated with poor clinical and functional outcomes. ${ }^{9}$ In our study, there was only a $17 \%$ (5/29) failure rate after embolization, which is an improvement for endovascular treatment compared with the studies described above. Such a rate may be the result of improvements in diagnostic imaging, a better understanding of the pathophysiology of SDAVF, further developments in microcatheter and microwire technology, or the technical experience of the operators regarding use of liquid embolic agents.

Ethylene vinyl alcohol (Onyx) is a relatively new liquid embolic agent used to treat cerebral arteriovenous malformations and fistulas. ${ }^{24-26}$ Because of the physical properties of the agent, this may allow a longer, more controlled injection with better penetration of the vascular bed (ie, venous aspect of the fistula) compared with conventional liquid agents, which polymerize immediately on contact with blood (Fig 2). However, in our series there was a 10\% (2/20) failure rate with cyanoacrylate glue and a $33.3 \%$ (3/9) failure rate with Onyx. This finding may be related to the experience the authors have with the injection of glue. Since 2003, a total of 3 small case series have described the use of Onyx in the treatment of SDAVFs. ${ }^{24,27,28}$ To the best of our knowledge, our series of 9 patients, in whom SDAVF was treated with Onyx, is the largest to date.

The goal of treatment of SDAVF is to arrest neurologic deterioration. Studies have shown no significant correlation with duration of symptom onset and the extent of cord edema on MR imaging. ${ }^{29} \mathrm{~A}$ trend has suggested that earlier exclusion of the fistula correlates with improved motor function. ${ }^{10}$ In general, studies suggest that bladder function, if affected, does not recover. ${ }^{16,30,31}$ In our series, we found a similar correlation with the duration of symptoms and treatment outcome. Improvement in motor function after treatment was more likely to occur than improvement in micturition dysfunction. Patients should be monitored with clinical examination and MR imaging after treatment; however, at present no statistical data have suggested correlation between resolution of T2-weighted cord hyperintensity and clinical outcome..$^{29,31-33}$ The persistence of flow voids despite treatment should prompt further spinal angiography to exclude persistent fistula from the same or adjacent level with collateral flow.

In our series, 14 of 15 patients demonstrated increased T2weighted medullary signal alterations on diagnostic MR imaging, and 6 of 15 patients showed cord expansion, most compatible with edema or venous congestion. Only a small portion of pa- 
tients showed an association between clinical improvement and a decrease in signal alterations and cord expansion (On-Line Tables 2-4). Furthermore, only $42 \%$ of our patients experienced complete resolution of flow voids/vessels within the spinal canal, whereas Song et $\mathrm{al}^{20}$ reported a $73 \%$ resolution of flow voids/ vessels within the spinal canal after successful treatment in their series. Our imaging findings are similar to those reported in the previous literature. $^{29,32,33}$

Limitations of our study were the relatively small sample size (particularly the surgery group) and the retrospective, nonrandomized design. Another weakness of our study was that the delayed time of diagnosis was calculated on the basis of the time of symptom onset reported by the patient on evaluation in the clinic, often many months after symptoms had started. Thus, a possibility of recall bias exists. Furthermore, pre- and post-MR imaging studies were not available in more than $50 \%$ of our patients; therefore, the sensitivity of this imaging technique in this study was limited.

\section{CONCLUSIONS}

Endovascular treatment of SDAVFs can result in good clinical outcomes. Surgery remains the treatment of choice when safe embolization of the proximal radicular draining vein cannot be obtained or because the shunting artery of the SDAVF also supplies the anterior spinal, posterior spinal, or radioculomedullary artery.

Disclosures: James Robertson-UNRELATED: Payment for Development of Educational Presentations: Codman Endovascular, Comments: Nurse Radiographer Course 2012, departmental grant provided.

\section{REFERENCES}

1. Lv X, Li Y, Yang X, et al. Endovascular embolization for symptomatic perimedullary AVF and intramedullary AVM: a series and a literature review. Neuroradiology 2012;54:349-59

2. Takai K, Taniguchi M. Comparative analysis of spinal extradural arteriovenous fistulas with or without intradural venous drainage: a systematic literature review. Neurosurg Focus 2012;32:E8

3. Narvid J, Hetts SW, Larsen D, et al. Spinal dural arteriovenous fistulae: clinical features and long-term results. Neurosurgery 2008; 62:159-66; discussion 166-67

4. Jellema K, Tijssen CC, van Gijn J. Spinal dural arteriovenous fistulas: a congestive myelopathy that initially mimics a peripheral nerve disorder. Brain 2006;129:3150-64

5. Koenig E, Thron A, Schrader V, et al. Spinal arteriovenous malformations and fistulae: clinical, neuroradiological and neurophysiological findings. J Neurol 1989;236:260-66

6. Van Dijk JM, TerBrugge KG, Willinsky RA, et al. Multidisciplinary management of spinal dural arteriovenous fistulas: clinical presentation and long-term follow-up in 49 patients. Stroke 2002;33:1578-83

7. da Costa L, Dehdashti AR, terBrugge KG. Spinal cord vascular shunts: spinal cord vascular malformations and dural arteriovenous fistulas. Neurosurg Focus 2009;26:E6

8. McCutcheon IE, Doppman JL, Oldfield EH. Microvascular anatomy of dural arteriovenous abnormalities of the spine: a microangiographic study. J Neurosurg 1996;84:215-20

9. Steinmetz MP, Chow MM, Krishnaney AA, et al. Outcome after the treatment of spinal dural arteriovenous fistulae: a contemporary single-institution series and meta-analysis. Neurosurgery 2004;55: 77-87; discussion 87-88

10. Sivakumar W, Zada G, Yashar P, et al. Endovascular management of spinal dural arteriovenous fistulas. A review. Neurosurg Focus 2009;26:E15

11. Krings T, Geibprasert S. Spinal dural arteriovenous fistulas. AJNR Am J Neuroradiol 2009;30:639-48
12. Houdart E, Redondo A, Saint-Maurice JP, et al. Natural history of an incidentally discovered spinal dural arteriovenous fistula. Neurology 2001;57:742-43

13. Hurst RW, Kenyon LC, Lavi E, et al. Spinal dural arteriovenous fistula: the pathology of venous hypertensive myelopathy. Neurology 1995;45:1309-13

14. Jellema K, Canta LR, Tijssen CC, et al. Spinal dural arteriovenous fistulas: clinical features in $\mathbf{8 0}$ patients. J Neurol Neurosurg Psychiatry 2003;74:1438-40

15. Muralidharan R, Saladino A, Lanzino G, et al. The clinical and radiological presentation of spinal dural arteriovenous fistula. Spine 2011;36:E1641-47

16. Behrens S, Thron A. Long-term follow-up and outcome in patients treated for spinal dural arteriovenous fistula. J Neurol 1999;246:181-85

17. Mourier KL, Gelbert F, Rey A, et al. Spinal dural arteriovenous malformations with perimedullary drainage. Indications and results of surgery in 30 cases. Acta Neurochirurg 1989;100:136-41

18. Niimi Y, Berenstein A, Setton A, et al. Embolization of spinal dural arteriovenous fistulae: results and follow-up. Neurosurgery 1997;40: 675-82, discussion 82-83

19. Westphal M, Koch C. Management of spinal dural arteriovenous fistulae using an interdisciplinary neuroradiological/neurosurgical approach: experience with 47 cases. Neurosurgery 1999;45:45157, discussion 457-58

20. Song JK, Gobin YP, Duckwiler GR, et al. N-butyl 2-cyanoacrylate embolization of spinal dural arteriovenous fistulae. AJNR Am J Neuroradiol 2001;22:40-47

21. Eskandar EN, Borges LF, Budzik RF Jr, et al. Spinal dural arteriovenous fistulas: experience with endovascular and surgical therapy. J Neurosurg 2002;96:162-67

22. Sherif C, Gruber A, Bavinzski G, et al. Long-term outcome of a multidisciplinary concept of spinal dural arteriovenous fistulae treatment. Neuroradiology 2008;50:67-74

23. Andreas RH, Barth A, Guzman R, et al. Endovascular and surgical treatment of spinal dural arteriovenous fistulas. Neuroradiology 2008;50:869-76

24. Corkill RA, Mitsos AP, Molyneux AJ. Embolization of spinal intramedullary arteriovenous malformations using the liquid embolic agent, Onyx: a single-center experience in a series of 17 patients. J Neurosurg Spine 2007;7:478-85

25. Nogueira RG, Dabus G, Rabinov JD, et al. Preliminary experience with Onyx embolization for the treatment of intracranial dural arteriovenous fistulas. AJNR Am J Neuroradiol 2008;29:91-97

26. Weber W, Kis B, Siekmann R, et al. Endovascular treatment of intracranial arteriovenous malformations with Onyx: technical aspects. AJNR Am J Neuroradiol 2007;28:371-77

27. Warakaulle DR, Aviv RI, Niemann D, et al. Embolisation of spinal dural arteriovenous fistulae with Onyx. Neuroradiology 2003;45:110-12

28. Nogueira RG, Dabus G, Rabinov JD, et al. Onyx embolization for the treatment of spinal dural arteriovenous fistulae: initial experience with long-term follow-up. Technical case report. Neurosurgery 2009;64:E197-98; discussion E8

29. Aghakhani N, Parker F, David P, et al. Curable cause of paraplegia: spinal dural arteriovenous fistulae. Stroke 2008;39:2756-59

30. Jellema K, Tijssen CC, van Rooij WJ, et al. Spinal dural arteriovenous fistulas: long-term follow-up of 44 treated patients. Neurology 2004;62:1839-41

31. Song JK, Vinuela F, Gobin YP, et al. Surgical and endovascular treatment of spinal dural arteriovenous fistulas: long-term disability assessment and prognostic factors. J Neurosurg 2001; 94:199-204

32. Cenzato M, Versari P, Righi C, et al. Spinal dural arteriovenous fistulae: analysis of outcome in relation to pretreatment indicators. Neurosurgery 2004;55:815-22, discussion 22-23

33. Atkinson JL, Miller GM, Krauss WE, et al. Clinical and radiographic features of dural arteriovenous fistula, a treatable cause of myelopathy. Mayo Clin Proc 2001;76:1120-30 